\title{
El fin de la historia en Hegel y Marx*
}

\author{
The End of History in Hegel and Marx
}

\author{
Israel Sanmartín Barros \\ israel.sanmartin.barros@gmail.com \\ Investigador contratado Programa Isidro Parga Pondal \\ Universidad de Santiago de Compostela \\ Plaza de la Universidad, $\mathrm{s} / \mathrm{n}$ \\ 15782 - Santiago de Compostela - La Coruña \\ España
}

\section{Resumen}

En este trabajo nos centraremos en las construcciones teóricas de Hegel y Marx alrededor de la idea de "fin de la historia" y también en la opinión que han suscitado en los diferentes autores sus ideas finalistas. Jugaremos, así, con las ideas de fin en Hegel y Marx, pero también con las de toda una serie de estudiosos que han polemizado sobre el tema en los últimos años. Partiendo de esas premisas teóricas, el objetivo fundamental de esta investigación es mostrar qué fines de la historia presentan Hegel y Marx y cómo se imbrican el uno en el otro. La idea es mostrar la tradición teórica del término y su genealogía en esos dos autores. Para ello recurriremos a una matriz de análisis descriptiva a fin de localizar cómo y dónde expresan los dos autores la idea de fin de la historia. Tras presentar sus ideas, buscaremos similitudes y diferencias en la arquitectura histórica y teórica de los conceptos de fin de la historia, todo ello partiendo de la idea de que Hegel es el iniciador de dicho concepto y Marx, su continuador. Analizaremos dichas ideas desde una perspectiva teórica.

\section{Palabras clave}

Georg W. F. Hegel; Karl Marx; Libertad.

\begin{abstract}
In this work, focus will be on Hegel's and Marx's theoretical constructions on the notion of "the end of History" and also on the opinions that have emerged among a variety of authors from such ideas of finality. We will be thus using the notions of end in Hegel and Marx but also those of a number of scholars that have controversially discussed the issue in recent years. Building on these theoretical premises, the fundamental purpose of this work is to show what ends of history Hegel and Marx postulate and how one is interwoven in the other. The idea is to bring out the historical tradition of the term and its genealogy back to these two authors. To this end, we will resort to a descriptive analysis approach to locate how and where these two authors expound the notion of the end of History. Once we have elaborated on the two authors, we will look for similarities and differences in the theoretical and historical architecture of the ends of history, all of which on the principle that Hegel is the initiator of the notion of end of History and Marx his follower. These notions will be analyzed from a theoretical perspective on the basis of their development of ideas.
\end{abstract}

\section{Keywords}

Georg W. F. Hegel; Karl Marx; Liberty.

Recebido em: 29/4/2013

Aprovado em: 28/6/2013

* Este trabajo está insertado en el marco del proyecto de investigación "Milenarismo plenomedieval (siglos XI-XIII): historia, historiografía e imagen" (EM 2012/046), financiado por la Xunta de Galicia. 
El de fin de la historia no es un concepto nuevo, pese a que en los años 90 del siglo XX se haya puesto de moda gracias a los escritos del politólogo Francis Fukuyama. De alguna forma San Agustín ya establece la idea de fin al hablar de un Juicio Final y al hacer girar toda la semántica medieval alrededor de la idea de salvación. Hegel y Marx serán otros de los grandes develadores de la idea de fin de la historia, entendido como fin ideológico de la humanidad y no como fin de los acontecimientos o como fin del mundo. En este trabajo nos centraremos, por tanto, en las construcciones teóricas de Hegel y Marx alrededor de la idea de "fin de la historia" y también en la opinión que han suscitado en los diferentes autores sus ideas finalistas. Jugaremos, así, con las ideas de fin de Hegel y Marx, pero también con las de toda una serie de estudiosos que han polemizado sobre el tema en los últimos años. Conectar la escatología y la ciencia de las últimas cosas con la política no es nada novedoso en la historia. Como hemos avanzado, ya lo habían hecho tanto San Agustín en la Ciudad de Dios como todas las ideologías milenaristas de la Edad Media. En los siglos XVIII y XIX el debate de "el fin de la historia" resurgió de nuevo con los escritos de Hegel (Fenomenología del espíritu y Filosofía de la historia) y Marx, quien rechazó el idealismo filosófico de Hegel y construyó su propia filosofía de la historia como la dialéctica del conflicto de clases. Para él, el partido comunista representaba la resolución final del conflicto de clases, porque rompía la antítesis entre capital y trabajo. Marx fue el primero de los sucesores de Hegel que precisaron que estaba confundido con que el fin de la historia representaba la emergencia del estado prusiano. Mientras Hegel creía que todo lo real era racional, Marx intentó hacer un mundo ideal. Partiendo de esas premisas teóricas, el objetivo fundamental de esta investigación es mostrar qué fines de la historia presentan Hegel y Marx y cómo se imbrican el uno en el otro. La idea es mostrar la tradición teórica del término y su genealogía en esos dos autores. Para ello recurriremos a una matriz de análisis descriptiva para localizar cómo y dónde expresan los dos autores la idea de fin de la historia. Tras presentar sus ideas, buscaremos similitudes y diferencias en la arquitectura histórica y teórica de los conceptos de fin de la historia, todo ello partiendo de la idea de que Hegel es el iniciador de dicho concepto y Marx, su continuador. Analizaremos estas ideas desde una perspectiva teórica.

\section{¿Cómo enunció Hegel el fin de la historia?}

¿Sostuvo Hegel alguna vez que la historia había llegado a su fin? ¿De qué fin se trababa? No hay mucho acuerdo al respecto. Para unos era difícil encontrar en los textos de Hegel la frase "el fin de la historia", pero otros sí que la identificaban. Sea como fuere, el sistema filosófico de Hegel exige el fin de la historia como conclusión y no hay duda de que hay suficientes evidencias para pensar que la asume en varios apartes de su obra (ANDERSON 1999, p. 17-31; MICHÉA 1992, p. 58-60). Veamos cuales son esos fragmentos.

1) En La fenomenología, Hegel califica la historia como la evolución consciente del espíritu en la sucesión de sus formas temporales hasta la meta del saber absoluto de sí mismo. A pesar de la contundencia de esa afirmación, 
el conocimiento absoluto no trae el fin de la historia, como se entiende tradicionalmente, sino que para llegar al fin se necesitan conocer los componentes de la historia universal de acuerdo con las demandas de una nueva necesidad moral. Según ese razonamiento, es un error basarse en el capítulo VIII de La fenomenología del espíritu para entender como Hegel interpreta filosóficamente la historia: a) como la historia actual entendida como "el ser en el tiempo", desbordando la vida y la muerte del ser social; b) como el nivel de abstracción de la anterior, es decir, como la filosofía de la historia; y c) como un intento de encontrar las causas profundas de la historia y envolver la creación en modelos históricos y elegir entre ellos (ESPOSITO 1982, p. 355-365).

2) En La filosofía del derecho, Hegel declara que el presente se había liberado de su barbarismo en el examen de las instituciones y que la verdad había dejado de ser "extramundana". Esto facilitaría que se hiciera objetiva una verdadera reconciliación que revelase al Estado como la imagen y realidad de la razón. Hegel, en La filosofía del derecho, describe el estado prusiano como el fin de la evolución política (BEDFORD 1994, p. 371-376). Hegel creyó en el fin de la historia porque creía en el derecho, puesto que sabía que el Estado moderno requería de un sistema jurídico basado en la verdad y que debía evitar el relativismo (PÉREZ 1993-1994, p. 171-172).

3) En las Lecciones para la filosofía de la historia, para Hegel, la meta a la que tiende el proceso histórico mundial es la libertad, que una vez lograda permanece invariable a pesar de eventos y condiciones. Uno de los primeros 102 pensadores que concibe la historia como un proceso racional desde la política económica es Hegel, especialmente en Lecciones sobre la filosofía de la historia universal, donde expresa que la historia sería entendida como un proceso de autorrealización del espíritu a través de diferentes fases en las que superaría su alineación. Por esa razón Hegel decía que "buscaremos en la historia un fin universal, el último fin del mundo; no un fin privado de un espíritu subjetivo" y defendía que aprenderíamos por medio de la razón que no podemos estar interesados en ningún fin privado y finito, "sino tan solo en el fin absoluto" (HEGEL 1974 , p. 205), es decir, no sería una cuestión de la razón individual, sino de la razón como algo absoluto. Desde esa idea central, Hegel emplea las categorías de variación, rejuvenecimiento, razón, idea (con relación a la libertad), espíritu de la gente, etnicidad y Estado (el fin del espíritu es el autoconocimiento). Hegel entiende la explicación de la historia como un proceso dialéctico y la reflexión sobre el Estado como un todo que implica una estructura tripartita formada por la familia, la sociedad civil y el Estado (VARGAS 1997).

4) En Lecciones sobre la historia de la filosofía, Hegel anuncia que estaría surgiendo una nueva época en el mundo, cuando reseña que el espíritu del mundo ha logrado eliminar a toda existencia objetiva extraña y captarse finalmente a sí mismo como absoluto. Esos son los cuatro argumentos de los que podemos partir para justificar el fin de la historia en Hegel (MICHÉA 1992, p. 58-60). Para muchos autores, como Perry Anderson, Hegel nunca planteó el fin de la historia, pero resulta fácil describirlo como un concepto que fue deducido a partir de él. Anderson considera que Hegel no enunció la frase ni la noción por dos razones: 
a) La última instancia de su filosofía no era la historia sino el espíritu, y la historia se presentaba, junto a la naturaleza, tan solo como una de sus facetas (PÉREZ 1993-1994, p. 177-178). La superación de la escisión entre ambas se concibe como un resultado más que como un final. Hay que entender que Hegel vio la Revolución francesa como la máxima expresión del espíritu moderno y que pensó en la totalidad del objeto-sujeto, ya que el sujeto y el objeto son una unidad y no existen por separado (cuestión que es clave en Hegel). Para Hegel, el espíritu es una matriz común al sujeto y al objeto y con la noción de espíritu trata de explicar por qué sujeto y objeto son inseparables. El espíritu se identifica con el sujeto porque es pensamiento de sí mismo y con el objeto porque puede pensarse como otro negándose a sí mismo. Para Hegel, la historia es la realidad sin más y también el proceso de toma de conciencia de sí mismo y del espíritu (BOBURG 1989, p. 235-242).

b) Hegel casi nunca habla de "ende" (final) o "schluB" (conclusión), sino que se refiere a "ziel" (meta), "zweck" (finalidad) o "resultat" (resultado). La razón es muy sencilla: en alemán no existe una palabra que combine los dos sentidos de la palabra "fin" en inglés (o en español), por un lado el de "final" y por otro el de "propósito" (a Hegel le interesaba sobre todo la segunda de esas acepciones) (ANDERSON 1999, p. 121-129).

De la síntesis hegeliana se desprende un fin de la historia más como una consumación filosófica que como un estado social definitivo y no deja de ser admisible que aquella implique en principio una variante de esta. Hegel no fue considerado un teórico del fin de la historia en el siglo XIX, cuando su reputación se identificó más con sus doctrinas sobre la naturaleza, la lógica y la política. Fueron estas las que provocaron controversia incluso para un historiador tan profundo como Marx. El concepto del fin de la historia, con toda su ambigüedad contemporánea, debió aguardar a "el fin de I'histoire" de Kojève para significar algo nuevo y distinto.

Todas estas argumentaciones fueron rebatidas por muchos otros autores que mostraban que el Hegel maduro sí explicitaba el fin de la historia. De tal forma, Hegel, en La filosofía de la historia y en La filosofía del espíritu, constata la reivindicación dialéctica del fin de la historia como un inevitable "todo" del dinamismo interno de la razón (DASILVA; KANJIRANTHINKAL 1993, p. 3-8). Para Hegel, el fin de la historia no es una mera posibilidad, sino que es algo que está ocurriendo tanto en el mundo como en la filosofía, lo que, además, expresa claramente: "it is not the end of History that the World becomes rational" (HEGEL 1956, p. 328). Y, en otro pasaje, señala: "at the end of History, the full realization of the total humanity - the product of the totality of humanity in history is freedom itself. Universal History is the progression in the consciousness of freedom - a progress that we must recognize as necessary" (HEGEL 1956, p. 30). Con esto queda rebatida la tesis de Anderson.

Otros autores argumentan que hay dos significados para describir el fin en Hegel, uno absolutista y otro de época, que no es absolutista. La mayoría de los comentaristas insisten en la visión absolutista, pero hay una síntesis de la dos, aunque no es plausible (BERTHOLD-BOND 1988, p. 14-29). Para otros, tampoco 
habría duda de que Hegel habla del fin de la historia, aunque dudan sobre el significado del concepto (ANKERSMIT 1989, p. 137-153).

Para entender mejor lo que se ha explicado hasta este momento, es necesario profundizar un poco más en el concepto de fin de la historia de Hegel. Con tal motivo, nos detendremos a examinar los elementos históricos, políticos y filosóficos que ayudan a articular dicho concepto en Hegel.

\section{La construcción del concepto de fin de la historia en Hegel}

Sea como fuere con relación a las diferentes interpretaciones, en la configuración del concepto de fin de la historia de Hegel intervienen conceptos y elementos histórico-políticos y filosóficos que abordaremos a continuación. Ahondando en los primeros, especialmente en la cuestión del estado social definitivo, la consecuencia del análisis hegeliano fue la justificación de la sociedad burguesa que surge con la Revolución Industrial y que llega al poder político con la Revolución Francesa. En realidad, quiera o no, Hegel planteó el carácter necesario y permanente de esa sociedad, y sus interpretaciones políticas posteriores fueron una consecuencia de esas reflexiones filosóficas.

\section{Los fundamentos histórico-políticos}

La desilusión de Hegel con la Revolución Francesa, que debía asegurar el desarrollo constante del proceso dialéctico por medio del cual se producían los cambios históricos, se da a partir de la amputación del territorio alemán por parte del Gobierno revolucionario francés. A partir de ese momento se confirma para Hegel el valor histórico universal del capitalismo y la resignación ante lo que él juzga su carácter inevitable. Hegel, ante la desembocadura de la Revolución en el capitalismo, asume que es inútil tratar de destruirlo, sobre todo en el momento de plenitud y expansión de las conquistas napoleónicas. Decepcionado, pues, con la Revolución Francesa como ideal, se decide a considerarla realidad y así operó en Hegel la transposición teológica del problema histórico en todas sus connotaciones económicas, políticas y sociales.

Otros conceptos fundamentales histórico-políticos son los referentes al Estado y a la sociedad civil (BAHTI 1992, p. 76-79). Hay que matizar que Hegel nunca vio con interés el concepto de "mano invisible" y siempre concibió la sociedad civil desde la ética. Creía que había tres clases en la sociedad civil: la clase inmediata, la clase de los negocios y la clase universal (Hegel no distingue entre empleados y empleadores). Ese sistema de clases juega un rol significativo en el concepto de libertad en Hegel, puesto que el filósofo piensa que la sociedad civil moderna proporciona un contexto para la libertad humana, aunque sea una libertad que no es la misma para todos. Hay que tener en cuenta que, para Hegel, las instituciones también forman parte del desarrollo de la libertad (WILLIAMS; SULLIVAN; MATTHEWS 1999, p. 31-37).

El Estado, por tanto, emerge a partir de la realización de la libertad humana y de la sociedad civil, pero Hegel no ve la forma final del Estado como algo que se impone, sino como un proceso diario que va creciendo día a día en relación con los individuos. Así, la sociedad civil surge desde la familia y el Estado, desde 
las limitaciones de la sociedad civil, pero la sociedad civil no es suficiente en sí misma desde el punto de vista de Hegel, que no acepta el laissez-faire de la sociedad comercial. Para él, la mano invisible no trabaja con perfección y tiene que estar ayudada por el Estado, sobre todo en los periodos de crisis. Para Hegel, el Estado se edifica al fin del proceso histórico como la monarquía constitucional, con lo que es difícil negar un tinte autoritario en el Estado ideal de Hegel. Esta afirmación es contraria a la que sostienen las lecturas liberales de Hegel, como la de Shlomo Avineri, quien, contrariando tanto la crítica marxista como de la de ciertos liberales como Popper y su escuela, defiende que la teoría del Estado de Hegel es compatible con el liberalismo (AVINERI 1972). Las lecturas liberales de Hegel identifican el Estado capitalista con la última evolución del Espíritu absoluto, es decir, con el fin de la historia (WALSH 1994, p. 182-190).

Marx, en la Crítica de la filosofía del Derecho Público, niega que el Estado sea la síntesis de toda la vida humana, institucional, económica, jurídica y política. El Estado, para Marx, es una superestructura, una emanación de la base económica y social en la cual las contradicciones que se producen en la economía, en las relaciones sociales de producción y en la sociedad civil se expresan magnificadas. La crítica de Marx es el primer debate sobre el fin de la historia. Para Marx, las contradicciones de clase son las contradicciones entre dos estratos sociales de naturaleza diferente que tienen elementos diferenciables y contrapuestos (SERRANO CALDERA 1991, p. 53-66).

\section{Los principios filosóficos}

Pasando a los conceptos filosóficos del fin de la historia, es importante reseñar la importancia de la filosofía de Hegel en el debate teórico-político del mundo contemporáneo. Según esta línea de pensamiento, Hegel fue desde su posición idealista mucho más revolucionario que los que proclaman constantemente la revolución de palabra y la negación de los hechos (el marxismo oficial devino profundamente reaccionario y antidialéctico al congelar el desarrollo de la sociedad en un dogma, que, en términos políticos, significó la consagración del poder absoluto y de la autocracia). Retornar a Hegel, pues, significa, para algunos autores, volver a las raíces del pensamiento revolucionario, a una de las fuentes más importantes del cambio y del pensamiento dialéctico, ya que en la obra de Hegel están las claves del mundo contemporáneo, en especial en sus tesis sobre el valor histórico y la universalidad (SERRANO CALDERA 1991, p. 53-66). Siguiendo con la cuestión filosófica, otra cuestión fundamental de Hegel es la del espíritu. Hegel entiende la historia como una manifestación de un proceso metafísico que se refiere al desarrollo del espíritu. De hecho, para entender a Hegel, hay que comprender que su filosofía se basa en la realización del espíritu. La filosofía de Hegel es una mezcla de filosofía y religión (cristiana) para entender la idea de geist (aunque en cuanto al aspecto de la religión algunos difieren y afirman que solo lo utiliza en su provecho).

Para algunos, el concepto de espíritu en Hegel es similar al concepto de Dios, un Dios panteísta, material y espiritual; pero no es así. Hegel se refiere al espíritu como razón y no como a la fuerza sobrenatural de las religiones 
antiguas y modernas; es el espíritu como fuerza que crea el hombre, la materia y la historia; es la racionalidad total y el desarrollo absoluto y es la perspectiva integral de lo humano y la sustancia de la historia (SERRANO CALDERA 1998).

Hegel, a comienzos del siglo XIX, deja intuir por primera vez el fin de la historia como un sistema en el que se consolida la propiedad privada, en un tiempo en que ha culminado todo el recorrido de la historia superando todas las contradicciones. De esa forma, entiende que se ha producido la unificación del espíritu consigo mismo en el capitalismo, en el liberalismo y en la organización jurídico-política que sucede al inicio del siglo XIX. Hegel entiende que con esa situación se ha pasado de la dialéctica del espíritu objetivo a la dialéctica del espíritu absoluto $y$, en consecuencia, se ha llegado al fin de la historia. En resumen, el espíritu se aliena y se desarrolla mediante un proceso dialéctico de contradicciones, contradicciones del mismo espíritu en sus diferentes manifestaciones y formas de expresión, en un marco en el que todas las expresiones tienen la misma naturaleza y la dialéctica es única, universal, homogénea, simple y apriorística. La historia termina cuando recorre su espíritu circular históricamente con la aparición del capitalismo económico y del liberalismo político.

\section{El significado del fin de la historia}

La idea del fin de la historia en Hegel descansa sobre la historia de la filosofía. En esa idea, la filosofía de la historia está subordinada a la filosofía general, con lo que Hegel sigue el proceso que ha sido observado en la filosofía misma. Como consecuencia, la historia mundial es el espíritu que se muestra gradualmente de varias formas en el mundo hasta alcanzar la libertad al precio que sea (esto ha sido interpretado por muchos como una puerta abierta al totalitarismo y una constatación del pensamiento reaccionario de Hegel). El proceso de la historia mundial es teleológico (ver el Hegel de La filosofía de la historia), de tal forma que el desarrollo del espíritu empieza en Oriente y se completa en Occidente hasta terminar en un estado al estilo europeo protestante (la lógica interna de la historia lleva a la forma completa de la libertad) (WILLIAMS; SULLIVAN; MATTHEWS 1999, p. 24-31). Hegel ve cada uno de los períodos de la historia como las etapas de ese proceso y abre sus ojos a cada período que asume la forma de volksgeit o espíritu nacional (TERRAY 1990, p. 37-41).

En definitiva, el fin de la historia de Hegel representa el agotamiento de las posibilidades del desarrollo del espíritu y representa el momento en que la sociedad civil y el Estado alcanzan la plena realización racional y, por consiguiente, cuando se logra la identidad entre la realidad y la racionalidad. "Todo lo real es racional y todo lo racional es real" es la esencia de La fenomenología del espíritu. Para algunos autores, el fin de la historia de Hegel aparece en sus trabajos de madurez, sobre todo en La filosofía de la historia y La filosofía del espíritu, obras en las que Hegel ve la reivindicación dialéctica del fin de la historia como un inevitable "todo" del dinamismo interno de la razón (DASILVA; KANJIRANTHINKAL 1993, p. 3-8).

La manipulación más profunda de Hegel es convertir el inmovilismo en el fin de la historia. Hasta Hegel, cualquier movimiento conservador había sido 
platónico. Había postulado la existencia de una edad de oro pretérita desde la que se había producido una degeneración. Para salir de tal decadencia era, pues, imprescindible regresar al pasado. Hegel dota a la reacción de un finalismo aristotélico: la historia es un proceso de etapas de lo imperfecto a lo perfecto hacia un fin. La caverna deja de ser el principio de la historia para ser su culmen. La manipulación es completa. Y mientras al conservadurismo clásico se le podían exigir explicaciones sobre los perfiles del ideal pretérito, aquí se han borrado sus huellas: la edad de oro se presenta como una conquista; toda recriminación práctica es ociosa. La dialéctica de la historia somete el juicio sobre los hechos presentes a la consecución del fin necesario, determinista, de la parusía o final de los tiempos, que toma corporeidad en una intensificación completa del estado absoluto, el estado total. Hegel quiere legitimar como intelectual-orgánico el estado de la monarquía absoluta prusiana y su voluntad expansionista (DE DIEGO 2005). Hegel subvierte todo el arsenal teológico de lo escolástico vaciando sus términos de contenido, haciendo una transferencia de sacralidad hacia el Estado (HEGEL 1999, p. 65).

Hemos visto como se configura el fin de la historia en Hegel y como lleva a una justificación de la modernidad para crear una falsa idea de progreso, que es en realidad una congelación de la historia, del Estado y de todo (HELLER 1996, p. 95-110). Esto nos lleva a afirmar que Hegel no es un idealista de todos los días en el sentido moral, sino en el sentido profundo filosófico, un idealista que piensa que la realidad es conducida y pensada por las ideas. Podemos decir que, para una buena parte de académicos, Hegel es el autor que más importancia le da a las ideas y para quien el fin de la historia debe ser entendido como el triunfo del pensamiento racional y sus instituciones (CROPSEY 1995, p. 97-116).

\section{El fin de la historia en Marx}

Marx fue un gran promotor de la idea del fin de la historia entendido como un proceso dialéctico con un principio, un desarrollo y un fin extraído de Hegel (BARBERO ALZAMORA 1993). Pese a todo, hay que matizar que Marx se refería fundamentalmente al "fin de la prehistoria", como veremos a continuación.

Según muchos autores, Marx fue uno de los propagandistas de la idea del fin de la historia, ya que creía que las contradicciones de las sociedades serían superadas con la llegada de la utopía comunista. Incluso, se podría afirmar que la polémica del fin de la historia se dio hace más de un siglo, cuando Marx arremetió contra Hegel provocando una discusión unilateral. Sin embargo, aunque el fin de la historia esté identificado con Hegel y Marx, algunos autores precisan que Marx y Engels, como en el caso de Hegel, nunca usaron la frase "el fin de la historia". "Marx no dejó nada escrito sobre el fin de la historia sino que creyó que la creación de un orden harmónico basado en sus enseñanzas significaría el inicio de la historia de la humanidad; pero no el fin de ella" (TROFINENKO 1999, p. 21-30). Así, los marxistas entienden el fin del capitalismo como el fin de la prehistoria de la humanidad y el comunismo, como la gran culminación de la historia. En otro sentido, los neomarxistas creen que la revolución anticapitalista es definida como el fin de la historia y como la negación del fracaso de la 
civilización (RACHKOV 1994, p. 9-14). Esas opiniones no eran unánimes y otros críticos apreciaban en el Marx de Economic and Philosphic Manuscrits of 1844 la constatación de que habría un fin de la historia y que ese sería el comunismo (WILLIAMS 1997, p. 557-566).

El Marx joven y los socialistas de su tiempo no eran lo suficientemente lúcidos para ser utópicos y aceptaron el mito smithiano creyendo que bastaba con negar que el sistema establecido por el capitalismo representase "el fin de la historia" hegeliano y propugnar la continuidad del mismo desarrollo económico dentro de un marco de relaciones distinto. Y aunque Marx matizase posteriormente sus primeros esquemas, no los reemplazó con formulaciones simples y claras, de modo que el marxismo catequístico acabó basándose en las certezas del Marx joven y desconociendo las dudas del maduro (FONTANA 1992, p. 131). Profundizando en lo mismo, Marx habló de prehistoria refiriéndose a que estábamos en la prehistoria de la humanidad y que la historia comenzaría con el comunismo. Marx tuvo la suficiente fuerza crítica para constatar que no se podía hablar de "fin de la historia", sino del "fin de la prehistoria". Con eso certificaba que es con la modernidad cuando comienza la historia, puesto que lo anterior era la prehistoria. Para Marx, con la modernidad, el hombre llega a ser un sujeto histórico y con el socialismo se completaría ese proceso, pues el hombre pasaría de ser sujeto histórico a ser sujeto de la historia (LEGUINA 1990, p. 57-69).

Su explicación era muy clara. La división entre la fuerza trabajo, que es la 108 energía del obrero, y los medios de producción, que son propiedad del empresario, divide a la sociedad en clases, con lo que los propietarios de la fuerza de trabajo y los propietarios de los medios de producción obligan al obrero a sobrevivir en el sistema y a vender su trabajo. Para Marx, el capitalismo es la etapa más elevada, y la última, en la historia de la explotación humana, de la alienación y de la lucha de clases. La reunificación de los medios de producción, de la fuerza de trabajo, la supresión de la explotación y de la división de la sociedad en clases, lograría en su estadio más alto superar la alienación del trabajador con respecto al producto y al proceso de trabajo y, sobre todo, con respecto al sistema, restituyendo al hombre a su condición humana y a su plenitud universal (SERRANO CALDERA 1991, p. 11-13). Esa conceptualización se basa sobre todo en los escritos del joven Marx y tiene como fin la desalienación del hombre y la recuperación de su condición humana usurpada, así como la transformación económica, social y política del sistema que se funda sobre la explotación del hombre, el capitalismo, en el sistema que permite su liberación, el socialismo. La realización de la sociedad socialista mediante la revolución sería también la constatación de la universalidad del sistema político y del fin de la historia. Para Hegel, el fin de la historia es el fin de las posibilidades de desarrollo del espíritu. Ese el momento en el que se alcanza la plena realización racional de la sociedad civil y del Estado, en el que se logra la identidad entre la realidad y la racionalidad. Para Hegel, la historia de la humanidad se resuelve en el proceso dialéctico cuya meta es la libertad o la conciencia de libertad; lo particular y lo individual son sacrificados para que el espíritu realice su fin último. Por contra, 
Marx afirma que ha invertido los términos de la dialéctica hegeliana, poniendo la praxis en lugar de las ideas $y$, aunque criticaba abiertamente lo que llamamos izquierda hegeliana, es el más claro representante de la misma. Los escritos juveniles de Marx no fueron publicados hasta 1930 y, a pesar de que muchos marxistas se jactan de haber invertido los términos de la dialéctica hegeliana, han conservado de ella el método y la seguridad de que el suceder histórico obedece a una sola ley y a un único argumento basado en las relaciones de producción, y en los modos en que dichos medios son utilizados.

Cuando Marx argumenta que ha invertido los términos de Hegel no quiere decir otra cosa sino que el proceso dialéctico no tiene lugar en el nivel de las ideas sino en el de la realidad. Marx cree que el motor de la Historia son las clases. Negaba que la meta de la Historia se hubiera alcanzado en 1806 pero estaba próxima, y estaba convencido que bajo la dictadura del proletariado se lograría la sociedad sin clases (SUÁREZ 1996, p. 181-202).

Marx, en La crítica de la filosofía del derecho de Hegel y otros escritos, señaló que el análisis de Hegel era incompleto, pues percibía solo la primera fase de la enajenación, la positiva, pero no la fase subsiguiente, la negativa, en la que la enajenación se convierte en la expoliación que llevará a la revelación del obrero. La historia no termina, según Marx, con el capitalismo y, como pensaba Hegel, en la teoría de la enajenación, sino con la superación de la enajenación, es decir, con el fin del capitalismo y el advenimiento del socialismo.

El aporte fundamental del marxismo no es tanto el materialismo (lo que no se niega), sino su afirmación de que la realidad es una actividad sensible del hombre. La realidad asumida como práctica y como acción rompe con todo determinismo y con toda metafísica. Entre el hombre y la historia hay una acción recíproca y una relación dialéctica. El hombre con su acción construye la historia y se hace a sí mismo. Para Marx, la conciencia no es una realidad predeterminada del ser humano y no es algo que le haya sido dado de una vez por todas, sino algo que se hace en cada momento con nuestras acciones buenas y malas. La teoría de Marx es una ciencia de la historia y una filosofía de la praxis. El propósito del socialismo, sobre todo el esbozado en los textos del joven Marx, es el de lograr la realización plena del individuo, para lo que resulta imprescindible la transformación de los mecanismos del sistema capitalista basados en la explotación, la plusvalía, la acumulación indefinida y la cosificación y la separación de los factores de producción, en otros tantos fundamentos cuales sean la solidaridad, la distribución equitativa de los bienes, la remuneración conforme a las necesidades de la persona y la desalienación del trabajador mediante la reunificación de la fuerza de trabajo con los medios de producción. Como en el caso de Hegel, no es unívoca la idea de que Marx se refirió al fin de la historia. Así, para algunos autores, Marx piensa que la expresión "fin de la historia" se debía cambiar por "historia de los fines". Para Marx, quien hace la historia no son los pueblos, sino las clases y el concepto suyo de ideología se da como algo revolucionario. "La ideología es la praxis revolucionaria global: la construcción por la clase obrera del nuevo mundo. 
Y la historia acabaría con la revolución total" (LEFEBVRE 1973). Frente a ese razonamiento, otros argumentan que siempre había habido corrientes críticas dentro del marxismo (como el trotskysmo ortodoxo) que siempre dudaron del sistema y que creían en una "democracia obrera" (PALMER 1994, p. 168).

\section{Distinciones y coincidencias entre el fin de la historia de Hegel y el de Marx}

Una vez vistas las posturas de Hegel y Marx, es el momento de entresacar las diferencias y similitudes entre los conceptos de fin de la historia de Marx y de Hegel (CLAUSSEN 1999, p. 63-71). El punto de partida es el de que Marx es hegeliano en lo que se refiere a la descripción del desarrollo de la realidad más que en la meta que quiere alcanzar (BERKI 1990, p. 654-671). Hegel proporcionó a Marx una teoría de la historia dinámica y evolutiva basada en el conflicto, pero, para Marx, el rechazo del capitalismo no está basado en consideraciones morales o humanitarias, sino que deriva de la realidad empírica de la economía capitalista: a) solo el trabajo crea valor; la maquinaria, la tierra y el resto de los factores de producción no lo crean; b) el capitalista solo paga al trabajador un saldo de subsistencia y el trabajador produce un valor dos veces mayor al que obtiene como jornal; eso conlleva una plusvalía para el capitalista. Por último, la noción de revolución de Marx es el punto culminante de su filosofía especulativa e incluye una filosofía de la historia, una teoría de la lucha de clases, una teoría del Estado, el hecho histórico de la revolución y el mundo utópico (la sociedad comunista) (MACRIDIS; HULLIUNG 1996, p. 97-109).

110 La fama de Marx como padre del materialismo histórico se propagó a partir de El Capital y El manifiesto comunista. Marx aceptó de Hegel la dialéctica, pero con un uso distinto: no eran las ideas las que generaban las realidades, sino a la inversa. Donde Hegel hablaba de marcha de la humanidad hacia un grado mayor de conciencia de libertad, Marx constataba una meta distinta: la abolición de las clases sociales. Marx explicaba que los filósofos no se habían limitado a interpretar el mundo, sino que también lo habían cambiado. Para él, las realidades económicas eran el fundamento de todas las demás: políticas, culturales, religiosas, etc.Marx y Engels insistieron en sus aceradas críticas al hegelianismo en cuanto a que este descendía del cielo a la tierra cuando lo procedente era hacer el camino contrario. Para ellos, la historia era la historia de la lucha de clases, que tendría como resultado que el proletariado acabaría por quitarle la vida a la burguesía. La lucha por su liberación exigiría al proletario elevarse a clase dominante y ganar la batalla de la democracia. Para Marx, había una larguísima prehistoria en la que la burguesía había escrito su capítulo final y una historia futura que se abriría cuando se suprimieran los antagonismos entre capital y trabajo. Sería el triunfo de la necesidad (Manifiesto del partido comunista).

Eso todo se puede sintetizar en que Marx varió de manera radical la concepción hegeliana de la historia. Ambos idearon dos concepciones del final de la historia estrechamente vinculadas entre sí pero diferentes, que, a su vez, han tenido una gran influencia durante los últimos cuarenta años (RYAN 1994, p. 9-11). Cada crisis marxista tiende a producir relecturas de Hegel que abarcan las Lenin, Lukács y Gramsci hasta Marcuse. El marxismo aceptó la idea hegeliana 
de totalidad social con la idea del destino de la sociedad global como un todo (WISTRICH 1999, p. 3-7). Pasando a cuestiones más concretas, pasemos a enumerar las diferencias entre Hegel y Marx en relación con sus concepciones del fin de la historia:

a) Una diferencia fundamental entre Hegel y Marx son los agentes que intervienen en el devenir histórico. Para Hegel, los sujetos de la historia serían el espíritu y los seres individuales y, para Marx, las clases sociales y las fuerzas de producción, especialmente el proletariado. Para Marx, el proletariado, mediante la lucha de clases, daría los pasos para completar la tarea de la historia mundial. Por contra, para Hegel, la historia es el resultado de un proceso profundo del desarrollo del espíritu que, a su vez, reuniría las lecciones más importantes de la religión cristiana. El concepto clave de Hegel en la filosofía es el concepto de espíritu. En él descansa todo el idealismo hegeliano (WILLIAMS 2002, p. 557-566).

Por otro lado, para Marx, la historia la hacen las clases $y$, de ellas, en primer término la burguesía y, después, la obrera. Para Marx, solo hay historia en la medida que interviene la clase obrera, que es el agente que puede unir en sí el conocimiento, la voluntad y la utilización de las contingencias como determinismos. La clase obrera rechaza todo lo que ha tenido porque no tiene nada y porque no es nada; no tiene nada más que perder que sus cadenas. Para Marx, lo que llamamos historia no es más que la prehistoria de la humanidad, puesto que el autor conjetura que con la revolución proletaria se termina la prehistoria y empieza la historia (Marx abandonó su tesis de la primacía de la historia por la economía en El capital), que a su vez concluiría con una revolución total (LEFEBVRE 1973, p. 56-57). b) Como consecuencia de lo anterior, Hegel es un idealista en el sentido de que la realidad está pensada por una idea (los idealistas creen que las realidades intelectuales maquetan el mundo); por contra, Marx y los materialistas piensan que la materia es la raíz de todo (PARAMIO 1990, p. 59-64). Marx invirtió la prioridad de lo real y lo ideal construyendo todo el ámbito del conocimiento, religión, arte, cultura y filosofía en base a una superestructura totalmente determinada por el modo material imperante de producción. c) Marx sostuvo, en la Crítica a la filosofía del derecho, que el análisis de Hegel es incompleto, pues percibe solo la primera fase de la enajenación, pero no la subsiguiente, cuando la negación se convierte en explotación, en el momento en que los objetos producidos se vuelven contra su creador al transformarse en el núcleo del sistema de explotación (PALMER 1994, p. 168). Así, según Marx, la historia no termina en el capitalismo, como pensaba Hegel, sino en la superación del capitalismo y el advenimiento del socialismo. Por lo tanto, tanto para Hegel como para Marx, la realización de la condición de universalidad en sus respectivos sistemas conducirá al fin de la historia en su doble acepción (CALDERA 1991, p. 13-19).

d) Marx y Hegel ofrecen dos concepciones del proceso histórico y del fin de la historia diferentes. Para Hegel, el fin de la historia se produce en el sentido en que se produce el fin de la filosofía (el fin de las ideas). La idea del fin de la historia de Hegel descansa en la idea de la visión acumulativa de la historia de la filosofía; le gustaría que su sistema filosófico fuera la culminación lógica de 
toda la filosofía previa y de todos los debates de la filosofía de su tiempo. Hegel intenta una filosofía de la totalidad, pero es una totalidad que no se reduce a recoger todos los puntos de vista sino solo algunos (los que considera él importantes). Con esa metodología, entiende el desarrollo de la filosofía hacia unas metas concretas (su discurso es triunfalista) y, en función de eso, historia, filosofía, escuelas de pensamiento, instituciones y líderes políticos son vistos como parte de una evolución hacia el presente. La historia mundial es la forma en la que se manifiesta el espíritu en el mundo y la historia del mundo es el proceso que resulta de desarrollarse y realizarse ese espíritu.

Paralelamente, para Hegel, el fin de la historia es el agotamiento de las posibilidades del desarrollo del espíritu, que evoluciona merced a sus propias contradicciones, que se van resolviendo hasta agotarse. Además, el fin de la historia es el momento en el que se alcanza la plena realización racional de la sociedad civil y del Estado y en el que se logra la identidad entre la realidad y la racionalidad (todo lo racional es real y viceversa). Esa es la esencia de la Fenomenología del espíritu.

En cambio, para Marx, la historia es el desarrollo de la humanidad hacia un ideal, el comunismo. Marx se refiere al fin de la historia en Economic and Philosphic Manuscripts of 1844, obra en la que defiende que el fin de la historia está implícito dentro de la historia misma. Igualmente, Marx presenta su relato de la historia en el Manuscripts de 1844 apolíticamente, como un conjunto de hechos. Marx explica que el comunismo representa la diversidad de todos los desarrollos

112 históricos humanos y que la filosofía de la historia tiene la capacidad de dar significado y sentido a las actividades sociales e individuales (eso lo diferencia de Hegel y Kant). Marx considera que ese proceso no solo consistiría en un proceso intelectual, sino también en un proceso de desarrollo económico, ya que para él lo individual y lo social están estructurados por necesidades económicas. Marx cree que Hegel está incluido dentro del grupo de filósofos que fracasan en ver los "intereses reales" de la historia. Para Marx, Hegel es el modelo representativo de la visión de la historia guiada por un sujeto "extrasuperterrestre" (WILLIAMS 2002, p. 557-566). En ese punto de la argumentación, Marx no entiende a Hegel, ya que para este el espíritu tiene cualidades trascedentes y emerge en el trabajo de los procesos sociales y políticos. "Un hegeliano diría que su concepción está tan apegada a la realidad como la explicación del comunismo de Marx, pero Marx entiende la historia como la creación del hombre a través de su trabajo y no como la emergencia de la naturaleza del hombre" (MARX 1970, p. 145). En sus visiones de la historia, Marx y Engels son monistas y dogmáticos. Marx es tan arrogante como Hegel y ambos nunca están preparados para ver su punto de vista como una de las visiones posibles del mundo; se apropian de todas las visiones y las confunden con la suya (WILLIAMS 2002, p. 557-566).

Para Marx, el fin del capitalismo es el fin de la prehistoria de la sociedad humana, puesto que, según él, la labor de la historia es transformar al individuo humano de objeto a sujeto de la historia (MARX 1971, p. 21).

e) Marx pone el acento en la finitud de la historia y Hegel, en la finalidad. Hegel habla de la finalidad a través de la historia y de las luchas históricas, 
cuando la filosofía ha devenido práctica, es decir, política. Marx quiere mostrar que la historia continúa y que el Estado hegeliano inagotable y heraclíteo se hundirá. Para Marx, la historia existe como obra de una práctica política, la revolución, que es una realidad producida por la acción, que, a su vez, produce un conocimiento (la historia es activa y reemplaza a la filosofía). Marx habla de una revolución total con el final de todas las alienaciones y la creación de un mundo que somete la necesidad y se libera de las constricciones (LEFEBVRE 1973, p. 43-44).

f) El marxismo representa, según algunos autores, una ruptura epistemológica con relación al hegelianismo y no una simple inversión de las posturas hegelianas. Según algunos exégetas, más asociados a posturas conservadoras, sería una simple inversión que conserva del hegelianismo la seguridad de que el acontecer histórico obedece a una sola ley y a un único argumento basado en las relaciones de producción, que dependen de los medios para lograrla y de los modos en que dichos medios son utilizados.

g) Hegel solo habla de la lucha de clases y esta alcanzaría su plenitud con el período industrial. En Marx, es muy diferente la perspectiva: la clase obrera asumiría la misión de continuar la historia y conducir su destino (LEFEBVRE 1973, p. 46-47).

Además de diferencias, también existen similitudes entre las visiones de la historia de Marx y la de Hegel. Pasemos a ver en detalle las similitudes. a) El desarrollo de la historia humana abarca diferentes épocas y etapas; b) Esas etapas representan una diferenciación entre los desarrollos de Oriente y Occidente; c) La historia mundial es progresiva; hay una evolución desde lo más primitivo hasta lo más moderno; d) La libertad humana representa una de las metas principales del desarrollo progresivo; e) Hay diferentes puntos de culminación respecto a la sociedad, pero los hay. Para Hegel, el punto culminante es el mundo protestante alemán y, para Marx, la sociedad comunista; f) El punto final es dinámico, está en continuo proceso; g) Hegel y Marx tienen un punto de vista teleológico. Piensan que hay un esencialismo en la historia; subestiman los eventos en la historia mundial y creen en la historia mundial como algo necesario; h) Para ellos, no hay solo una mejora material, sino también cultural y moral; i) En su visión de la historia, Marx y Hegel son dogmáticos y monistas. Son monistas porque creen que el único principio que puede mover la humanidad es la producción material y son dogmáticos porque no creen que haya otro principio rector de la historia que el que ellos consideran. El genio de Marx le permite una arrogancia intelectual que estaría mostrada en Hegel; j) Las teorías de la historia de Hegel y Marx tienen un injustificable optimismo; para Hegel y Marx las cosas tienden a ir a mejor (WILLIAMS 1997, p. 557-566); k) Hegel y Marx se refieren a la "Historia" y, para ambos, el fin de la historia es el momento en que se alcanza la plena realización racional de la sociedad; I) Hay otros futuros para la humanidad, pero Hegel y Marx parecen mantenerse ajenos a ellos. Marx y Hegel presentan la historia a partir de sus nociones de espíritu y proletariado revolucionario y sobre ambos conceptos ponen la responsabilidad para el futuro lejos de los individuos y de las entidades que parecen ir más allá de su control; m) Marx solo es entendible frente a Hegel; 
quien no trabaje a Hegel no puede comprender a Marx, cuya obra es un diálogo con aquel. Toda la obra de Marx está concebida como una contradicción filosófica a los planteamientos de Hegel: la fuerza del trabajo que se trasfiere a la materia prima y la enajenación negativa de Marx, el Estado como superación de todas las contradicciones en Hegel y como magnificación de todas las contradicciones en Marx, las situaciones económicas como producto del desarrollo del espíritu en Hegel y la concepción racional o ideológica de una sociedad como producto de las contradicciones en Marx.

En definitiva, Hegel privilegia el tiempo y el espacio, la intuición y el concepto, el sujeto y el Estado; Marx, la naturaleza, la revolución total, y la clase obrera, que le sirven como alternativa o como referencia privilegiada. Los fines para Marx existen, no en la razón de la historia como conocimiento, sino como racionalidad inmanente, superior a la irracionalidad religiosa y a la incierta racionalidad. Lo que Marx altera de Hegel es el motor que propulsa el proceso. El motor, para Marx, son la aspiración y el deseo de los grupos específicos (familias, naciones y clases) que constituyen la raza humana. Por tanto, Marx se opone a Hegel en la concepción de que no es la conciencia del hombre la que determina su existencia, sino la existencia social la que determina su conciencia. Así, Marx crea su materialismo en oposición al hegelianismo. En la filosofía de la historia, ese materialismo está expresado en el importante rol que se le da al trabajo y a la economía (DESMOND 1989, p. 39-40).

\section{Conclusión}

El concepto de final de la historia no es nuevo, ya que se trata de una expresión clásica que remite directamente a la interpretación de la filosofía de la historia propuesta por Hegel y Marx. Para ambos teóricos germanos, la historia se entiende en términos de proceso dialéctico: un curso del tiempo impulsado por leyes deterministas que atraviesa unos estadios perfectamente comprensibles, incluso previsibles, que se consuman en uno postrero (determinación del ciclo que conduciría a su terminación) y cuya culminación otorga pleno sentido y realidad al desarrollo mismo de los acontecimientos. La historia, a través de sus fases o estadios, sucede y se sucede, pues, según una lógica de progreso, que, siguiendo el viejo patrón de la teleología aristotélica (los conceptos se asemejan solo en esto) y una vez alcanzado su fin, cesa en su movimiento de perfección para disfrutar del reposo. Ese es el fin y la meta de la historia: que su objetivo se resuelva en la norma, que la historia se normalice, lo cual no implica su paralización ni su muerte o defunción, es decir, su término o su finalización. El fin es el telos, el resultado, la salida. Por decirlo aun de otro modo: la historia sigue el rumbo, pero ya ha encontrado su rumbo (RODRÍGUEZ 2002).

El historicismo de Hegel se ha convertido, "para bien o para mal", en parte de nuestro bagaje intelectual contemporáneo: es habitual encontrarse con razonamientos como que la humanidad ha avanzado a través de una serie de estados de conciencia desde la época primitiva hasta el presente y que a esos estados corresponden formas concretas de organización social (tribal, esclavista, teocrática o sociedades igualitarias democráticas). Hegel fue el primer filósofo en 
hablar el lenguaje de la sociedad moderna al afirmar que el hombre era producto de un ambiente histórico y social concreto, en contraposición a las teorías del derecho natural que conciben al hombre como un conjunto permanente de atributos naturales (Hegel detallaba que el hombre había cambiado su ambiente natural mediante la aplicación de la ciencia y de la tecnología).

Por su parte, Marx ha sido el mejor propagandista de la idea de fin de la historia al sostener que la meta de la historia sería la sociedad comunista. Marx se apropió para sus propios fines de amplios segmentos del sistema de Hegel. Marx aceptaba de Hegel el concepto de historicismo fundamental de los asuntos humanos y la noción de que la sociedad humana ha evolucionado en el tiempo desde estructuras sociales primitivas a otras más complejas y altamente desarrolladas. Hegel y Marx están de acuerdo en que el proceso histórico era fundamentalmente dialéctico y que las formas primitivas de organización social y política contenían contradicciones internas que se hicieron evidentes con el tiempo y que llevarían a su destitución. Marx compartía con Hegel la posibilidad de un fin de la historia, pero Marx difería de Hegel acerca de qué clase de sociedad habría cuando la historia llegara a su fin. Marx creía que el Estado liberal no lograba resolver una contradicción fundamental, la del conflicto de clases, la lucha entre la burguesía y el proletariado y, por eso, concluía que la universalización de la libertad y del Estado liberal era solo la victoria de la libertad para la burguesía. Hegel creía que la realización del espíritu se había resuelto adecuadamente al llegar al fin de la historia mediante el reconocimiento filosófico de la libertad en el Estado liberal; por contra, Marx estimaba que, para las sociedades liberales, el hombre seguía alienado, porque, en ellas, el capital se había convertido en amo y señor del hombre y lo controlaba. El fin marxista de la historia llegaría solo con la victoria de la verdadera clase universal, el proletariado, y la realización de una utopía comunista global que pondría término a la lucha de clases de una vez por todas. Así, el fin de la historia, para Hegel, era el Estado liberal y, para Marx, la sociedad comunista. Y Marx volvió el historicismo de Hegel contra este.

\section{Referencias bibliográficas}

ANDERSON, P. Los fines de la historia. Barcelona: Anagrama, 1999.

ANKERSMIT, F.R. Historiography and postmodernism. History and Theory, Middletown, Vol. XXVIII, no 2, p. 137-153, 1989.

AVINERI, Shlomo. Hegel and the Modern State. London: Cambridge University Press, 1972.

BAHTI, Timothy. Allegories of History. Literary historiography after Hegel. Baltimore: The Johns Hopkins University Press, 1992.

BARBERO ALZAMORA, Miguel. ¿EI fin de la tontería? Uruguay: Ediciones de Juan Darién, 1993.

BEDFORD, David. God, nature and the end of History. History of European Ideas, London, Vol. 19, no 1-3, p. 371-376, 1994. 
BERKI, R.N. Through and through Hegel: Marx's road to communism. Political Studies, New Jersey, Vol. XXXVIII, no 1, p. 654-671, March 1990.

BERTHOLD-BOND, Daniel. Hegel's eschatological vision: does history have a future?. History and Theory, Middletown, Vol. XVII, no 1, p. 14-29, 1988.

BOBURG, Felipe. Hegel y la revolución francesa. Revista de Filosofía, Madrid, Año XXII, no 65, p. 235-242, Mayo-Agosto 1989.

CLAUSSEN, Detlev. Els intel.lectuals, entre la "crisi de la raó" i la "fin de la historia, L'espill, Barcelona, no 1, p. 63-71, 1999.

CROPSEY, J. The End of History in the Open-ended Age? The Life Expectancy of Self-evident Truth. In: MELZER, Arthur M.; WEINBERGER, Jerry; ZINMAN, Richard M. (eds.) History and the idea of Progress. Ithaca and London: Cornell University Press, 1995. p. 97-116.

DASILVA, Fabio B.; KANJIRANTHINKAL, Mathew J. Politics at the end of History: essays in post-modernist thought (major concepts in politics and political theory. New York: Peter Lang Publishing, 1993. Vol. 3.

DE DIEGO, Enrique. Hegel o el Estado totalitario. La ilustración liberal, no 13 y 14. Disponible en: http://www.libertaddigital.com/ilustracion_liberal/ articulo.php/341. Consultado el: 4 de julio de 2005.

DESMOND, William. Hegel and his critics: philosophy in the aftermath of Hegel. New York: State University of New York Press, 1989.

ESPOSITO, Joseph L. Hegel, absolute knowledge, and the end of History. Clio, Indiana, Vol. 12, no 4, p. 355-365, Summer 1983.

FONTANA, Josep. La historia después del fin de la historia. Reflexiones acerca de la situación actual de la ciencia histórica. Barcelona: Crítica, 1992.

GADAMER, H. G., Los fundamentos filosóficos del siglo XX. In: VATTIMO, G. (comp.), La secularización de la filosofía. Hermenéutica y postmodernidad. Barcelona: Gedisa, 1992. p. 92-101.

HEGEL, G. W. F. Lecciones sobre la filosofía de la historia universal. Madrid: Revista de Occidente, 1974.

Lecciones de Filosofía de la Historia. Madrid: Alianza Editorial, 1999. . Lectures on the Philosphy of History. New York: Dover, 1956.

HELLER, Agnes, El último estado de la Historia (memoria, rememoración y bildung: sobre la teoría de la modernidad en Hegel). Isegoría, no 14, Madrid, p. 95-110, octubre 1996.

LEFEBVRE, Henri. La violencia y el fin de la historia. Buenos Aires: Ediciones Siglo Veinte, 1973.

LEGUINA, Joaquín. El final de una historia. Sistema, Madrid, no 98, p. 57-69, Septiembre 1990. 
MACRIDIS, Roy; HULLIUNG, Mark. Contemporary political ideologies: movements and regimes. New York, Harper Collins Collegue Publishers, 1996.

MARX, Karl. Contribution to the Critique of Political Economy. London: Lawrence \& Wishart, 1971.

Economic and philosophic manuscripts. London: Lawrence \& Wihart, 1970.

MICHÉA, Jean-Claude. Introduction. In: LEFORT, Bernard (coord.). De la fin de I' histoire. Paris: Éditions du Félin, 1992. p. 53-60.

PALMER, B. ¿Existe, si es que alguna vez existió, la clase obrera?. In: AA.VV. A Propósito del fin de la historia. Valencia: Edicions Alfons el Magnànim, 1994. p. 164-171.

PARAMIO, Ludolfo. Marxismo analítico. Claves, Madrid, no 7, p. 59-64, noviembre 1990.

PÉREZ HERRANZ, Fernando M. Historia e historia; en torno al propuesto fin de la historia. Anales de la Universidad de Alicante: historia contemporánea, Alicante, no 10-11, p. 158-179, 1993-94,

RACHKOV, P. A. The End of History as a sociosophical problem. Russian Studies in Philosophy, Vol. 33, North Carolina no 2, p. 9-14, 1994.

RODRÍGUEZ GENOVÉS, Fernando. Fukuyama y Huntington, en la picota. El Catoblepas, no 9, p. 7, noviembre 2002.

RUIZ S., Carlos. Heidegger y Hegel. Revista de Filosofía, Madrid Vol. XLI-XLII, p. 131-148, Nov. 1993.

RYAN, A. Introducción. In: AA.VV. A propósito del fin de la historia, Valencia: Edicions Alfons el Magnànim, 1994. p. 3-11.

SERRANO CALDERA, A. Hegel y Zubiri o el filósofo ante el desafío de una nueva ética. Disponible en: http://www.una.ni/ellacuria/hegel.htm. Consultado el 6 de abril de 1998 .

El fin de la historia: reaparición del mito. La Habana: Editorial 13 de marzo, 1991.

SUÁREZ FERNÁNDEZ, Luis. Corrientes del pensamiento histórico. Pamplona: Universidad de Navarra, 1996.

SUÁREZ, Alfonso G. ¿Réquiem por la historia? Claves, Madrid no 32, p. 56-57, mayo 1993.

TERRAY, Emmanuel. From Hegel to Marx. The saga of the dialectic. Encounter, London, p. 37-41, April 1990.

TROFINENKO. The end of the cold war, not History. Washington Quarterly, Washington, Vol. 13, no 2, p. 21-30, 1999. 
VARGAS, Gabriel. The Debate About the End of History and Global Democracy. In: LIGHT, Andrew; NAGEL, Mechthild (eds.). Race, Class, and Community Identity. New York: Humanity Books, 1997, p. 222-231.

WALSH, David. The Ambiguity of the Hegelian End of History. In: BURNS, Timothy (ed.). After History? Francis Fukuyama and his critics. Maryland: Rowman \& Littlefield Publishers, 1994, p. 182-190.

WILLIAMS, Howard. The End of History in Hegel and Marx. The European Legacy, London, Vol. 2, no 3, p. 557-566, 1997. ; SULLIVAN, David; MATTHEWS, Gwynn. Francis Fukuyama and the end of history. Cardiff: University of Waless Press, 1999.

WISTRICH, Robert. Reflections on The End of History. Midstream, New York, Vol. 3, no 1, p. 3-7, 1999. 